\title{
A brief review of the extraction technologies of azadirachtin, a plant-derived bio-pesticide
}

\author{
Chen Wanren and Li Hua*
}

School of Chemical Engineering and Energy, Zhengzhou University, Zhengzhou, 450001 China.

Accepted 22 January, 2018

\begin{abstract}
Due to the increasingly strict requirements of sustainable development and environmental protection, chemical pesticides have been gradually questioned for its damage to the environment and human health; therefore environment-friendly and pollution-free plant-derived pesticides are being paid more and more attention to. Azadirachtin (Azt) is a tetracyclic triterpene compound, which is extracted from the seeds, leaves and bark of plant neem (Meliaceae). As the most potential insect antifeedant and growth disturbance agent, it can be used to innovate different biological pesticides. In this article, the present status and progress of Azt extraction were reviewed and some new technologies were described in detail. The research orientation and prospect of Azt extraction techniques were also discussed.
\end{abstract}

Keywords: Meliaceae, microthermal, microwave, neem, polarization, triterpenoid, solubility, ultrasonic.

*Corresponding author. E-mail: lihua@zzu.edu.cn.

\section{INTRODUCTION}

Azadirachtin (Azt) is an effective botanical insecticide, it is widely used in agriculture. Conventional insecticides are synthetic chemicals which release synthetic pesticides into the environment, some of which causes serious damage to the ecological environment and human health. Plant-derived pesticide is biodegradable, environmentally clean and less toxic to non-target organisms (Jadeja et al., 2011; Kamaraj et al., 2018; Devatha et al., 2018; Subbanna et al., 2018). Azt, as a plant-derived pesticide, is the most potential one.

Azt is an insect growth disrupter, which acts by interfering with the insect endocrine signaling molecules, juvenile hormone and 20-hydroxyecdysone, leading to deleterious effects on development and reproduction (oocyte structure, fecundity, oviposition and egg viability) (Mordue et al., 2005; Abedi et al., 2014). Azt impacts on the nervous system (Qiao et al., 2013) and the insulinsignaling pathway (Shao et al., 2016), influences the oviposition behavior of various insects (Tomé et al., 2013). This is because it is non-toxic to vertebrates and has no genotoxicity for mammals, and is the research orientation of new pesticides.

Azt is a triterpenoid compound, extracted from the neem plant. It can inhibit feeding of many insects and arthropods; hinder the growth of them, thus arriving to the insecticidal effect (Ismadji et al., 2012). There are many extraction technologies, including supercritical fluid extraction, microwave method, ultrasonic method, homogenization extraction, rapid extraction and tank group type dynamic countercurrent extraction. In the present review, the principle, the research status and the merits and demerits of those methods were summarized, which can provide reference for the enterprises and research workers.

\section{NEW TECHNOLOGIES}

\section{Supercritical fluid extraction}

Supercritical fluid is the fluid between gas and liquid, possessing a dual characteristic of liquid and gas at the same time. Near the critical point, small changes of the systematic temperature or pressure can result in tremendous mutation of the solubility of a substance. So authors, in the current article, could change the properties of the supercritical fluid by changing the temperature so as to achieve the purpose of the selective 
extraction of various kinds of compounds. Effective constituent in solid material could be extracted efficiently by this method. Besides, the process could be operated in the oxygen-free and microthermal conditions. Therefore, it was suitable for the separation and purification of easily-oxidized substances and thermalsensitive substances. In addition, we could asperate the solvent from the mixtures by changing the systematic temperature or pressure, therefore there was no solvent pollution and the solvent can be recycled (Zhao et al., 2004).

With neem seed kernel, as the material, Peng et al. optimized the supercritical $\mathrm{CO}_{2}$ extraction technology by uniform design scheme (Peng et al., 2007). The influences of the extraction pressure, temperature, time and the volume of the entrainer methanol on the extraction effect were examined by the evaluation index of the quantity of Azt in the product. And the best extraction technology conditions were determined ultimately with pressure being $37 \mathrm{MPa}$, temperature $43^{\circ} \mathrm{C}$, time $165 \mathrm{~min}$ and the volume of the entrainer 13 $\mathrm{ml}$. Under these conditions, the extraction rate of the Azt in neem seed kernel was $0.37 \%$.

As $\mathrm{CO}_{2}$ has a small polarity, therefore supercritical fluid extraction technology with $\mathrm{CO}_{2}$ acting as the extractant is suitable for the separation of substances with small polarities instead of components with large polarities. Yet, owing to the large investment of the devices and complex operation in the supercritical fluid extraction, the equipment capability and operation level still remain to be further improved (Devatha et al., 2018), if it is to be applied to industrial production.

\section{Microwave-assisted extraction}

Microwave frequency is associated with the frequency of the molecular rotation. When microwave acts on the molecule, it can promote the rotational motion of molecule. If the molecule has a certain polarity, it can produce instantaneous polarization under the action of microwave electromagnetic field and quickly generate a large amount of heat at the same time, which promotes the rupture of the cell and makes the cell sap overflow and spread to the solvent. Since ability of absorbing microwave for different substances is different, we can maximize the microwave absorption of the wanted component by adjusting the frequency and power of microwave radiation, thus achieving the purpose of the selective extraction of some component and increasing the extraction rate. Microwave assisted extraction has the advantages of less reagent dosage, high extraction speed, high efficiency and high purity etc (Zhao et al., 2003; Zong et al., 2002) .

Experiments to extract the nimbin from neem seed were conducted by Zhao et al. with the aid of microwave (Zhao and Li, 2009). The effects of radiation time, solvent, material ratio and radiation power on the extraction ratio of nimbin were respectively examined, using HPLC to measure the content of extracted nimbin. It turned out that the best combination was: radiation time 3 min $\times 3$ times, methanol as solvent, microwave power $210 \mathrm{~W}$ and material ratio $1: 3(\mathrm{~kg} / \mathrm{L})$. Under these conditions, the extraction ratio of nimbin was $76.269 \%$.

The solvent used in microwave-assisted extraction is required to have polarity to a certain extent. And it's suitable for the extraction of components with large polarities. When we use this method to extract thermalsensitive components, the extraction temperature is hard to control (Zhao et al., 2004).

\section{Ultrasonic reinforcement extraction}

Ultrasonic reinforcement extraction is a kind of auxiliary solvent extraction technology. Its mechanism is that ultrasonic vibration produces and delivers strong energy, creating a lot of small holes in the medium (Wang et al., 2004). The small hole closes instantly and generates an instantaneous pressure of more than $3000 \mathrm{MPa}$. Strong cavitation effect makes the cell wall break and a large amount of entocyte overbrim. Ultrasonic reinforcement extraction has gained wide attention because of the characteristics of high extraction speed and high efficiency.

Nan et al. extracted nimbin by the method of ultrasonicassisted extraction (Nan et al., 2012). Single factor and orthogonal test analysis were conducted to determine the optimum extraction technology of ultrasonic-assisted extraction of nimbin. The ultrasonic frequency, ultrasonic power and solid-liquid ratio were taken as the reference factors. The analysis indicated that order of factors affecting the ultrasonic extraction of nimbin is: solid-liquid ratio > ultrasonic frequency > ultrasonic power. The best extraction technology conditions were: solid-liquid ratio is $1: 4$, ultrasonic frequency is $80 \mathrm{kHz}$ and ultrasonic power is $250 \mathrm{~W}$. Under the optimal conditions, the yield of nimbin crude extract reached $7.532 \%$.

The research about the mechanism of ultrasonic extraction, that is, ultrasonic cavitation effect, is still very preliminary. There is still a lot of research work needed to be carried out on the interaction between material and sound energy and the additional effects it causes. In addition, we need to do in-depth research about its application to the extraction of plant pesticides (Zhao et al., 2004).

\section{Homogenate extraction}

In the method of homogenate extraction, effective ingredients in living tissue are extracted through adding solvent to the biological tissue for tissue homogenate or defibrination. Yang et al. extracted nimbin from defatted 
neem seed with this method (Yang et al., 2008). The effects of different factors on extraction during the extraction process were studied and the optimum technology parameters for homogenate extraction were obtained as homogenate for one time and $3 \mathrm{~min}$ at one time with $100 \%$ methyl acetate at a ratio of solid to liquid of $1: 12(\mathrm{~g}: \mathrm{ml})$. The homogenate extraction with simple apparatus has the advantages of rapid, high efficiency and easy operation.

\section{Rapid extraction}

In the process of extraction, when the solvent comes into contact with the raw materials, the solvent will infiltrate into the internal cell tissue that contains solute and dissolves the solute therein, forming the intracellular solution within the tissue, whose concentration is higher than the solution around the raw material. Then the solute molecules or particles spread to the surface of the raw materials and then to the solvent, forming leaching solution around the raw material. When the concentrations of the intracellular solution and the leaching solution are equal, the diffusion process stops. Then the leaching solution shall be let out and leaching solution of low concentration or new solvent is added to continue to extract the materials, making the diffusion effect begin again till a new equilibrium is established (Duan et al., 2008).

Wang et al. compared the yield of extract and the quality percentage content of Azt $A$ and Azt B extracted by 4 kinds of methods: microwave, ultrasonic, conventional solvent and rapid extraction from neem seed (Wang et al., 2009). The total time passed through the rapid extraction process was $0.5 \mathrm{~h}$ and the extract yield was $3.39 \%$. The contents of Azt A and Azt B were 8.99 and $2.92 \%$, respectively. This result showed that the rapid extraction method exhibited the best efficiency. The granularity of neem powder in different extract time was, also, determined. It had found that unceasingly falling of the material granularity is an important factor that can affect the effect of rapid extraction.

\section{Multi-stage dynamic countercurrent extraction}

More than two dynamic extraction tank units in series are connected in multi-stage dynamic countercurrent extraction process (Ji and Chang, 2006). The extraction solvent successively transmits through each tank along the solute concentration gradient adversely from low to high. The solvent needs to maintain a certain period of extraction time with the materials and be recovered repeatedly. This technique mainly depends on the concentration gradient differences between the active ingredients in the solid phase and liquid phase, in which the active ingredients in the solid phase diffuse to the extraction solvent with a low initial concentration step by step and consequently the goal is achieved that the active ingredients in the solid phase are transferred to the liquid phase maximally.

Yang et al. optimized the process conditions of the extraction of azadirachtin from neem seeds by multistage dynamic countercurrent extraction with the method of response surface methodology (Yang et al., 2010). The effects of extraction temperature, methanol dosage and extraction time on extraction quantity of Azt were investigated. The results showed that the optimal conditions for multi-stage dynamic countercurrent extraction were that extraction is four-stage, extraction temperature is $32^{\circ} \mathrm{C}$, methanol dosage is $2.5 \mathrm{ml} / \mathrm{g}$ and extracting time is 34 min for every stage, under which the extraction quantity of Azt was $3.86 \mathrm{mg} / \mathrm{g}$.

Compared to the complex equipment needed by supercritical, microwave and ultrasonic extraction, multistage dynamic countercurrent extraction has the advantages of simple equipment, convenient operation, saving energy and strongly practical process. Most natural product extraction factory can build the multistage dynamic countercurrent extraction equipment by reforming the existing traditional equipments. Besides, the requirement of particle size for this method is not high. Neem seeds don't need shelling or deoiling, avoiding the loss of nimbin caused by deoiling. The extraction process is short and easy to realize industrialized production. And it has obvious advantages of saving solvent, increasing production of nimbin and efficiency (Yang et al., 2010).

\section{FUTURE REMARKS}

Azt constitutes a valuable alternative to the conventional insecticides for the pest control. It is environmentallyfriend botanical. Depending on the currently available literature, there are many research works on the extraction of the Azt and the technology is relatively mature. However, there still exists a problem that Azt is unstable under natural conditions, which has become the critical issue in restricting the industrialization and the popularization and application of Azt (Hu and Lu, 2009), and is sure to be the future research orientation of Azt preparations.

\section{REFERENCES}

Abedi Z., Saber M., Vojoudi S., Mahdavi V., Parsaeyan E. (2014). Acute, sublethal and combination effects of azadirachtin and Bacillus thuringiensis on the cotton bollworm, Helicoverpa armigera. J Insect Sci, 14: 1-9.

Devatha C. P., Jagadeesh K., Patil M. (2018). Effect of Green synthesized iron nanoparticles by Azardirachta indica in different proportions on antibacterial activity. Environ Nanotechnol Monitor Manag, 9(5): 85-94.

Duan Q. F., Yao C. C., Chen S. D., Wang Y. Q., An X. N. (2008). Present situation of study on extraction of azadirachtin and prospect on its application. Agrochemicals, 47(7): 483-486. 
Hu W. M., Lu X. L. (2009). Research progress on botanical insecticide azadirachtin. China Tea Processing, 29(4): 20-22.

Ismadji S., Kurniawan A., Ju Y. H., Soetaredjo F. E., Ayucitra A., Ong L. K. (2012). Solubility of azadirachtin and several triterpenoid compounds extracted from neem seed kernel in supercritical $\mathrm{CO}_{2}$. Fluid Phase Equilibria, 336: 9-15.

Jadeja G. C., Maheshwari R. C., Naik S. N. (2011). Extraction of natural insecticide azadirachtin from neem (Azadirachta indica A. Juss) seed kernels using pressurized hot solvent. J Supercritical Fluids, 56: 253258.

Ji Y. Y., Chang X. Q. (2006). Multi-stage dynamic countercurrent extraction technology and its application in the extraction of traditional Chinese medicine. Modern Chinese Med, 1(1): 27-30.

Kamaraj C., Gandhi P. R., Elango G., Karthi S., Rajakumar G. (2018). Novel and environmental friendly approach; Impact of Neem (Azadirachta indica) gum nano formulation (NGNF) on Helicoverpa armigera (Hub.) and Spodoptera litura (Fab.). Int $\mathrm{J}$ Biol Macromolecules, 107(1): 59-69.

Mordue A. J., Morgan E. D., Nisbet A. J. (2005). Azadirachtin, a natural product in insect control. In: L.I. Gilbert, K. latrou, S.S. Gill (Eds.), Comprehensive Molecular Insect Science, Elsevier Oxford, UK, pp. 117-135.

Nan Z., Sun R. G., Zhang H. P. (2012). Mufti-frequency ultrasonic assisted extraction of azadirachtin process. Technical Acoustics, 31(4): 86-89.

Peng L. X., Han B. J., Han H., Yin N. (2007). Supercritical $\mathrm{CO}_{2}$ extraction techniques for active components from neem seeds. Chinese J Trop Crops, 28(1): 101-104.

Qiao J., Zou X., Lai D., Yan Y., Wang Q., Li W., Deng S., Xu H., Gu H. (2013). Azadirachtin blocks the calcium channel and modulates the cholinergic miniature synaptic current in the central nervous system of Drosophila, Pest Manag Sci, 70: 1041-1047.

Shao X., Lai D., Zhang L., Xu H. (2016). Induction of autophagy and apoptosis via PI3K/ AKT/TOR pathways by Azadirachtin $A$ in Spodoptera litura cells. Sci. Rep., 6: 35482.

Subbanna A. R. N. S., Rajasekhara H., Stanley J., Mishra K.K., Pattanayak A. (2018). Pesticidal prospective of chitinolytic bacteria in agricultural pest management. Soil Biol Biochem, 116(1): 52-66.

Tomé H. V. V., Martins J. C., Correea S., Galdino T. V. S., Picançon M. C., Guedes R. N. C. (2013) Azadirachtin avoidance by larvae and adult females of the tomato leafminer Tuta absoluta. Crop. Prot, 46: 63-69.

Wang Q. F., Song Z. Q., Zhao S. Y., Gao H. (2004). Ultrasonic assisted process (UAP) for solvent extraction of azadirachtin from neem seed. Chem Industry Forest Prod, 24(1): 25-28.

Wang Y.Q., Ma L. Y., Zhang Z. Q. (2009). Rapid extraction of azadirachtin. World Pesticides. 31(3): 14-16.

Yang J., Luo X. R., Fan J, Yu D. (2010). Study on multi-stage dynamic countercurrent extraction process of azadirachtin from neem seeds. Agrochemicals, 49(6): 413-415.

Yang L., Li J. L. Zu Y, Zhao C, Li X, Li J. (2008). Homogenate extraction of azadirachtin A from Azadirachta indica seed. J Northeast Forestry Univ, 36(9): 65-67.
Zhao S. Y., Li H. Z. (2009). Microwave-assisted process for the extraction of nimbin from neem seed. Agrochemicals, 48(8): 561-563.

Zhao S. Y., Song Z. Q., Wang Q, Gao H. (2004). Progress on research of new extraction techniques for phytochemical pesticides. Chem Industry Forest Prod, 24(2): 102-106.

Zhao S.Y., Song Z.Q., Gao H., Wang Q. (2003). An effective method of microwave assisted process (MAP) for extraction of azadirachtin from kernel of Azadirachta indica A. Chem Industry Forest Prod, 23(4): 4750.

Zong Q. S., Lin J., Yan S. J., Wu Y. K., Zeng W. (2002). Microwaveinduced extraction of azadirachtin from neem seed shell. Yunnan Chem Technol, 29(6): 19-21.

Citation: Wanren C., Hua L. (2018). A brief review of the extraction technologies of azadirachtin, a plant-derived bio-pesticide. Afr J Eng Res, 6(1): 15-18. 